\title{
Inhibition of Nitric Oxide Production by Ethyl Digallates Isolated from Galla Rhois in RAW 264.7 Macrophages
}

\author{
Pil-Hoon Park ${ }^{2}$, Jin Hur ${ }^{1}$, Dong-Sung Lee ${ }^{3}$, Youn-Chul Kim³ , Gil-Saeng Jeong ${ }^{4}$ and Dong Hwan Sohn ${ }^{1, *}$ \\ ${ }^{1}$ Institute of Pharmaceutical Research and Development, Department of Pharmacy, Wonkwang University, Iksan 570-749, \\ ${ }^{2}$ College of Pharmacy, Yeungnam University, Gyeongsan 712-749, \\ ${ }^{3}$ Standardized Material Bank for New Botanical Drugs, College of Pharmacy, Wonkwang University, Iksan 570-749, \\ ${ }^{4}$ College of Pharmacy, Keimyung University, Daegu 704-701, Republic of Korea
}

\begin{abstract}
Galla Rhois and its components are known to possess anti-inflammatory properties. In the present study, we prepared equilibrium mixture of ethyl $m$-digallate and ethyl $p$-digallate isomers (EDG) from Galla Rhois and examined its effect on nitric oxide (NO) production in murine macrophage cell line. Treatment of RAW264.7 macrophages with EDG significantly inhibited NO production and inducible nitric oxide synthase (iNOS) expression stimulated by LPS, as assessed by Western blot and quantitative RTPCR analyses. We also demonstrated that EDG treatment led to an increase in heme oxygenase-1 (HO-1) mRNA and protein expression. EDG treatment also enhanced expression level of nuclear factor-erythroid 2-related factor 2 (Nrf2) in nucleus, which is critical for transcriptional induction of HO-1. Treatment with SnPP (tin protoporphyrin IX), a selective HO-1 inhibitor, reversed EDG-mediated inhibition of nitrite production, suggesting that $\mathrm{HO}-1$ plays an important role in the suppression of NO production by EDG. Taken together, these results indicate that EDG isolated from Galla Rhois suppresses LPS-stimulated NO production in RAW 264.7 macrophages via HO-1 induction.
\end{abstract}

Key Words: Ethyl digallate, Inducible nitric oxide synthase (iNOS), Nitric oxide, Nuclear factor-erythroid 2-related factor 2 (Nrf2), Heme oxygenase-1

\section{INTRODUCTION}

Inflammation is a complex biological response to protect tissues against injury, irritation or infection. During inflammation, the level of nitric oxide (NO) is enhanced and it exerts a defense against pathogens (Lowenstein et al., 1994). However, NO has pathological functions, as wells as physiological functions in many mammalian tissues (Kroncke et al., 1997). In many cases, appropriate levels of NO are important in the regulation of various physiological process, while abnormal excess of NO is produced by inducible nitric oxide synthase (iNOS) during inflammation and acts as a toxic radical that contribute to inflammatory tissue damage (Colasanti and Suzuki, 2000). Therefore, modulation of NO production by iNOS may represent a useful strategy for the treatment of inflammatory diseases.

Heme oxygenases $(\mathrm{HO})$ catabolize the first and rate-limiting step in the metabolism of heme into equimolar concentrations of free iron, carbon monoxide (CO), and bilirubin/ biliverdin (Maines, 1997). HO-1, a highly inducible isoform, is

\section{www.biomolther.org}

Open Access http://dx.doi.org/10.4062/biomolther.2011.19.4.419

pISSN: 1976-9148 elSSN: 2005-4483

Copyright $\odot 2011$ The Korean Society of Applied Pharmacology widely known to possess potent anti-inflammatory properties by reducing the production of pro-inflammatory cytokine production, or stimulating the production of anti-inflammatory cytokines, including interleukin-10 (Otterbein et al., 2003; Paine et al., 2010). Additionally, HO-1 over-expression protects against cytotoxicity induced by $\mathrm{NO}$ (Son et al., 2005). HO-1 expression is induced by binding of an upstream activator to the anti-oxidant response element (ARE) in its promoter region. Nuclear factor-erythroid-2-related factor (Nrf2), a transactivating protein, interacts with AREs and is known to play an essential role in the expression of HO-1 (Prawan et al., 2005).

Galla Rhois, the gall derived from the nutgall sumac tree, Rhus javanica, has been used for the treatment of various diseases, including skin disease, diarrhea, dysentery, hemorrhage, and leucorrhea in traditional oriental medicine. A number of tannin-derived components isolated from Galla Rhois have been shown to possess various biological activities, including anti-bacterial (Kang et al., 2008) and anti-metastatic/ anti-invasion of tumor cells (Ata et al., 1996). In addition, previously we demonstrated that equilibrium mixture of ethyl

Received Jul 29, 2011 Revised Sep 1, 2011 Accepted Sep 22, 2011

\footnotetext{
*Corresponding Author

Email: dhsohn@wonkwang.ac.kr

Tel: +82-63-850-6822, Fax: +82-63-854-6038
} 
$m$-digallate and ethyl $p$-digallate isomers (EDG), isolated by bioassay-guided fractionation of the ethanol extract of Galla Rhois, exhibited potent hepatoprotective effects on tacrineand nitrofurantonin-induced cyotoxicity in HepG2 cells (An et al., 2005). Further, recent studies have shown that tanninderived components, such as gallates, propyl gallates, and epigallocatechin-gallate (EGCG), suppress production of inflammatory cytokines in mast calls (Melgarejo et al., 2010), inhibit NF-kappa B and JNK activation in macrophages (Jung et al., 2010) and expression of leukocyte adhesion molecules in vascular endothelial cells (Murase et al., 1999), indicating that Galla Rhois and its constituents would be promising for the treatment of inflammatory disease.

In the present study, as part of our continuing effort to develop optimal anti-inflammatory agents, we demonstrated EDG from ethanol extract of Galla Rhois potently suppressed NO production in macrophages stimulated with LPS. Further, we examined the potential role of $\mathrm{HO}-1$ induction in EDG-mediated suppression of NO production.

\section{MATERIALS AND METHODS}

\section{Preparation of EDG and GA}

Equilibrium mixture of ethyl $m$-digallate and ethyl $p$-digallate isomers (EDG) and gallic acid (GA) were isolated from ethanol extract of Galla Rhois through bioassay-guided fractionation, as described by An et al., 2005 and its chemical structure is shown in Fig. 1. Galla Rhois was purchased from the University Oriental Drugstore, Iksan, Korea in October, 2004. A voucher specimen (No. WP04-296) was deposited at the Herbarium of the College of Pharmacy, Wonkwang University (Korea).

\section{Cell culture}

The murine macrophage-like cell line, RAW 264.7, was routinely cultured in Dulbecco's Modified Eagle Media (DMEM) supplemented with $2 \mathrm{mM}$ glutamine, antibiotics $(100 \mathrm{U} / \mathrm{ml}$ of penicillin-streptomycin), and $10 \%$ heat-inactivated fetal bovine serum (FBS) in a $37^{\circ} \mathrm{C}$ humidified incubator containing $5 \% \mathrm{CO}_{2}$

\section{Reagents}

All cell culture reagents were purchased from Gibco/Invitrogen (Grand Island, NY, USA). Lipopolysaccharide (LPS) from Escherichia coli serotype 026:B6 (tissue culture tested) and $\beta$-actin antibody was purchased from Sigma (St. Louis, $\mathrm{MO}$, USA). Antibodies against iNOS, $\mathrm{HO}-1$, and Nrf2 were purchased from Santa Cruz Biotechnology (Santa Cruz, CA, USA). Anti-rabbit and anti-mouse IgG conjugated to horseradish-peroxidase (HRP) were also purchased from Santa Cruz Biotechnology.

\section{Quantitative determination of nitrite levels}

Accumulated $\mathrm{NO}_{2}^{-}$(nitrite) in the cell culture media was used as an indicator of NO production and determined by the Griess method, as described previously (Lee et al., 2004). Briefly, RAW 264.7 macrophages were cultured in 6-well plates and stimulated with LPS $(100 \mu \mathrm{g} / \mathrm{ml})$ for $24 \mathrm{~h}$. Supernatants $(100 \mathrm{ml} /$ well) were then collected, mixed with equal volumes of Griess reagent and incubated at room temperature for $10 \mathrm{~min}$. $\mathrm{NO}_{2}^{-}$concentration was determined by absorbance at $550 \mathrm{~nm}$. The standard curve was constructed using the known concentrations of sodium nitrite $\left(\mathrm{NaNO}_{2}\right)$.

\section{iNOS enzyme activity assay}

RAW 264.7 macrophages were treated with LPS (100 ng/ $\mathrm{ml}$ ) in the absence or presence of EDG. Cells were collected and lysed by rapid cycles of freeze/thaw in the liquid nitrogen for three times followed by sonication. Fifty micrograms of lysate were incubated for $2 \mathrm{~h}$ at $37^{\circ} \mathrm{C}$ in $20 \mathrm{mM}$ Tris $(\mathrm{pH} 8.0)$ containing $10 \mu \mathrm{M}$ of flavin-adenine dinucleotide (FAD), $2 \mathrm{mM}$ of L-arginine, $1 \mathrm{mM}$ of $\mathrm{NADPH}$, and nitrate reductase. The amount of produced nitrite and nitrate was measured by the Griess reaction.

\section{Preparation of cellular extracts and Western blot analysis}

After treated with EDG for indicated time periods, nuclear and cytosolic extracts were prepared using a nuclear/cytosol fractionation kit (BioVision; Mountain View, CA, USA), according to the manufacturer's instructions. For Western blot analysis, samples with equal protein were loaded, separated by $10 \%$ SDS-PAGE, and then proteins in the gel were transferred onto nitrocellulose membranes. Nitrocellulose membranes were incubated with the specific primary antibodies, and then secondary antibodies conjugated with horse radish peroxidase (HRP). Immunoreactive bands were visualized by ECL detection reagents (KPL; Gaithersburg, MD, USA). The membranes were then stripped and reprobed with $\beta$-actin antibody for the loading control.

\section{RNA isolation, reverse transcription, and quantitative PCR (qPCR)}

After treated with EDG for the indicated time periods, total cellular RNA was isolated using RNeasy Micro Kit (Qiagen, Valencia, CA), according to the manufacturer's instructions. Total RNA was reverse transcribed using the RETROscript kit (Ambion; Austin, TX, USA) with random decamers as primers. Real time polymerase chain reaction (PCR) amplification was performed using SYBR Green PCR Core Reagents (TAKARA; Warrington, Japan). The relative amount of target mRNA was determined using the comparative threshold $(\mathrm{Ct})$ method by normalizing target mRNA Ct values to those for $\beta$-actin $(\Delta \mathrm{Ct})$. Statistical analysis of qPCR data was performed using $\Delta \mathrm{Ct}$ values. The primer sequences for target genes are indicated<smiles>C=CCOC(=O)c1cc(O)c(O)c(OC(=O)C2CC(O)C(O)C(O)C2)c1</smiles>

Fig. 1. Chemical structure of equilibrium mixture of ethyl $m$-gallate and ethyl $p$-gallate (EDG). 
in Table 1.

\section{Statistical analysis}

Data were analyzed by one-way analysis of variance (ANOVA) and Tukey's multiple comparison tests. Values are reported as mean $\pm S D$, and differences between groups were considered significant at $p<0.05$.

\section{RESULTS}

\section{EDG inhibits nitrite production in RAW 264.7 macro- phages stimulated with LPS}

To investigate whether equilibrium mixture of ethyl $m$-gallate and ethyl $p$-gallate (EDG) from Galla Rhois possesses anti-inflammatory properties, we examined its effect on NO production in LPS-stimulated RAW 264.7 macrophages. As shown in Fig. 2, LPS treatment markedly increased nitrite production in RAW 264.7 macrophages. However, when the cells were pretreated with EDG, LPS-induced nitrite production was significantly suppressed. Gallic acid (GA) is a major component of Galla Rhois and was shown to inhibit nitrite production in macrophages (Radtke et al., 2004). In this study, GA was isolated ethanol extract of Galla Rhois (An et al., 2005) and used as a reference drug. EDG treatment generated higher inhibitory effect on nitrite production than GA. EDG and GA do not affect cell viability by concentrations of $<200 \mu \mathrm{M}$, as assessed by MTT assay (data not shown).

Table 1. Primer sequences used for real time PCR

\begin{tabular}{clc}
\hline Gene & \multicolumn{1}{c}{ Sequences } & \\
\hline iNOS & 5'-TCC TAC ACC ACA CCA AAC-3' & Forward \\
& 5'-TCC TAC ACC ACA CCA AAC-3' & Reverse \\
HO-1 & 5'-TCT ATC GTG CTC GCA TGA AC-3' & Forward \\
& 5'-CAG CTC CTC AAA CAG CTC AA-3 & Reverse \\
3-actin & 5'-CTT TGC AGC TCC TTC GTT GC-3' & Forward \\
& 5'-ACG ATC GAG GGG AAT ACA-3' & Reverse \\
\hline
\end{tabular}

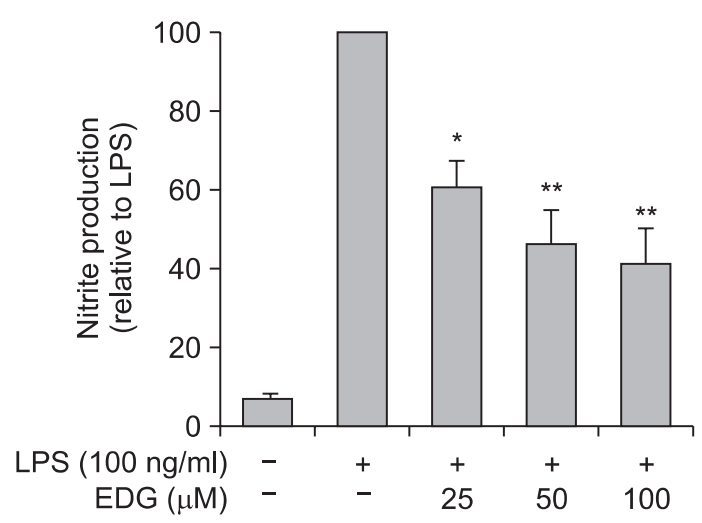

\section{EDG suppresses LPS-induced iNOS expression in RAW 264.7 macrophages}

Increased expression of inducible nitric oxide synthase (iNOS) is responsible for the excessive production of NO during inflammatory process (Mashimo and Goyal, 1999). To test the hypothesis that inhibition of nitrite production by EDG would be induced by suppression of iNOS expression, we examined whether EDG treatment affected iNOS expression in LPS-stimulated macrophages. As shown in Fig. 3A, LPS-stimulated iNOS protein expression was attenuated by treatment with EDG, without affecting the levels of internal control ( $\beta$-actin). Quantitative RT-PCR (qRT-PCR) analysis indicated that EDG treatment also significantly suppressed LPS-induced accumulation of iNOS mRNA (Fig. 3B). EDG also blocked the increase in iNOS enzyme activity induced by LPS (Fig. 3C). These findings indicate that EDG inhibits NO production through inhibiting induction of iNOS in LPS stimulated macrophages.

\section{EDG increases H0-1 expression and nuclear accumulation of Nrf2 in RAW 264.7 macrophages}

Heme oxygenase-1 (HO-1) regulates various inflammatory mediators and plays an important role in the regulation of inflammation. To test the hypothesis that inhibitory effect of EDG on NO production is mediated by $\mathrm{HO}-1$ induction, we first examined whether EDG treatment induces $\mathrm{HO}-1$ expression. As shown in Fig. 4A, EDG treatment $(100 \mu \mathrm{M})$ caused a slight increase in $\mathrm{HO}-1$ protein expression by $2 \mathrm{~h}$ treatment, caused a maximal increase by $8 \mathrm{~h}$ treatment, and remained significantly elevated by $24 \mathrm{~h}$ treatment. Quantitative RT-PCR analysis indicated that EDG treatment also caused a significant increase in HO-1 mRNA levels. HO-1 mRNA levels increased as early as $1 \mathrm{~h}$ after treatment with EDG, reached a maximum after $4 \mathrm{~h}$ of EDG treatment, and remained elevated after $18 \mathrm{~h}$ of treatment (Fig. 4B), which closely correlated with the pattern of $\mathrm{HO}-1$ protein expression. Next, we examined the effect of EDG on nuclear accumulation of Nrf2, since Nrf2 has been shown to play a critical role in $\mathrm{HO}-1$ expression. As shown in Fig. 4C, EDG treatment increased Nrf2 level in the nuclear fraction as early as $1 \mathrm{~h}$, and remaining elevated for $8 \mathrm{~h}$, implying that EDG treatment enhances expression of $\mathrm{Nr} 2 \mathrm{in}$ nucleus and the pattern is correlated with that of $\mathrm{HO}-1$

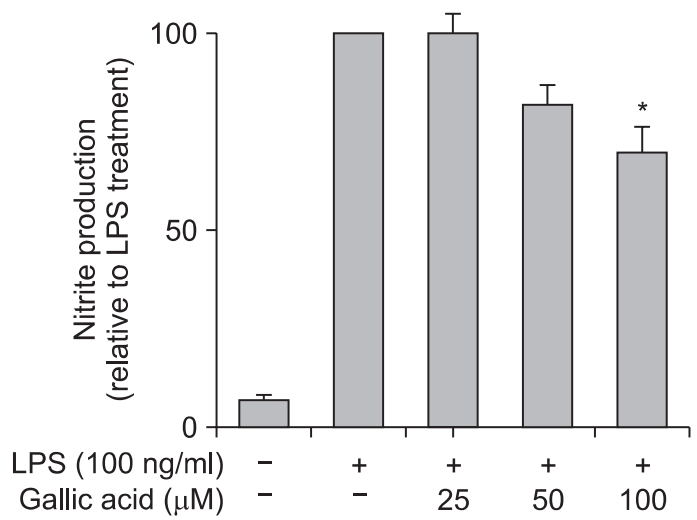

Fig. 2. EDG inhibits nitrite production in LPS-stimulated RAW 264.7 macrophages. Cells were pretreated with EDG or GA for $1 \mathrm{~h}$ and further stimulated with LPS $(100 \mathrm{ng} / \mathrm{ml})$ for $18 \mathrm{~h}$. The amount of nitrite in the cell culture media was measured as an indicator of NO production as described in Materials and Methods. Values are expressed as percent change compared to samples treated with LPS alone, means \pm S.D. $\mathrm{n}=3 .{ }^{*} p<0.05,{ }^{* *} p<0.01$ compared with LPS-treated samples. 
A

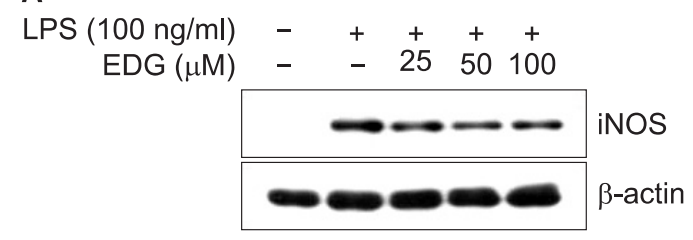

B

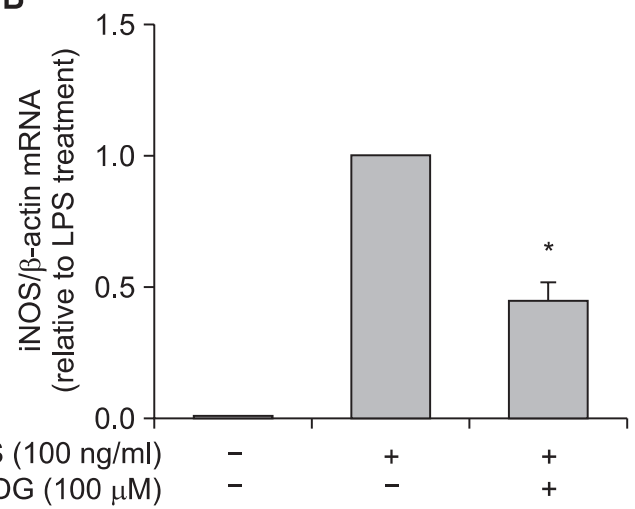

C

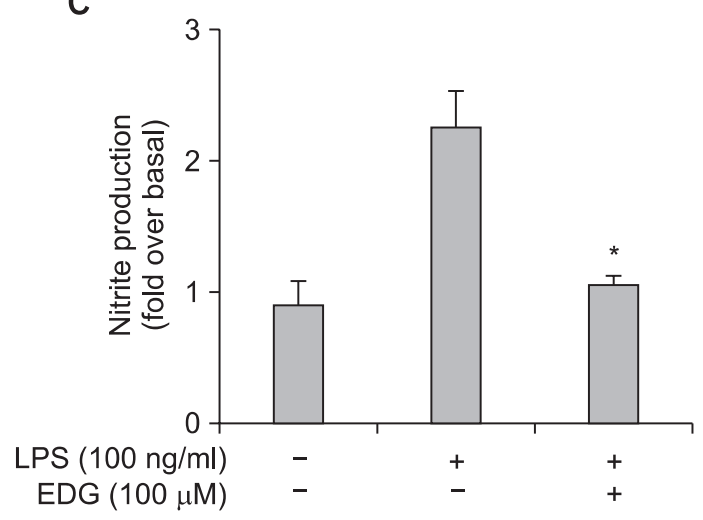

Fig. 3. EDG suppresses iNOS expression and iNOS enzyme activity in RAW 264.7 macrophages stimulated with LPS. (A) Cells were pretreated with EDG for $1 \mathrm{~h}$ prior to stimulation with LPS $(100 \mathrm{ng} / \mathrm{ml})$ for $24 \mathrm{~h}$. Whole-cell extracts were prepared and the protein level of iNOS was determined by Western blot analysis. $\beta$-actin was used for loading control. Images are representative of three independent experiments. (B) RAW 264.7 macrophages were pre-incubated with EDG $(100 \mu \mathrm{M})$ for $1 \mathrm{~h}$ and further incubated with LPS $(100 \mathrm{ng} / \mathrm{ml})$ for 18 h. Expression of iNOS mRNA was measured by quantitative RT-PCR. Values represent iNOS mRNA normalized to $\beta$-actin mRNA and data are expressed as fold change relative to LPS alone treated sample, means \pm S.D. $n=3 .{ }^{*} p<0.05$ compared with LPS-treated samples. (C) RAW 264.7 macrophages were pre-incubated with $100 \mathrm{mM}$ of EDG for $1 \mathrm{~h}$ followed by incubation with LPS (100 ng/ml) for another $18 \mathrm{~h}$. Cells were lysed by sonication and assayed for iNOS activity as indicated in the material and methods. Data are expressed as fold change relative to the sample treated with LPS alone, means \pm S.D. $n=3$. ${ }^{*} p<0.05$ compared with LPS-treated samples.

A

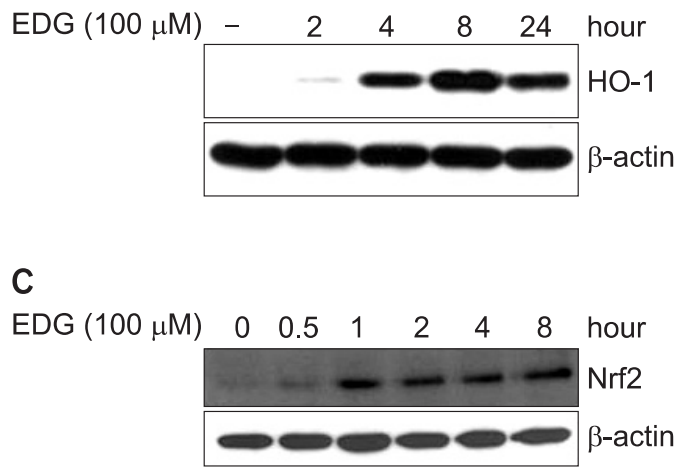

B

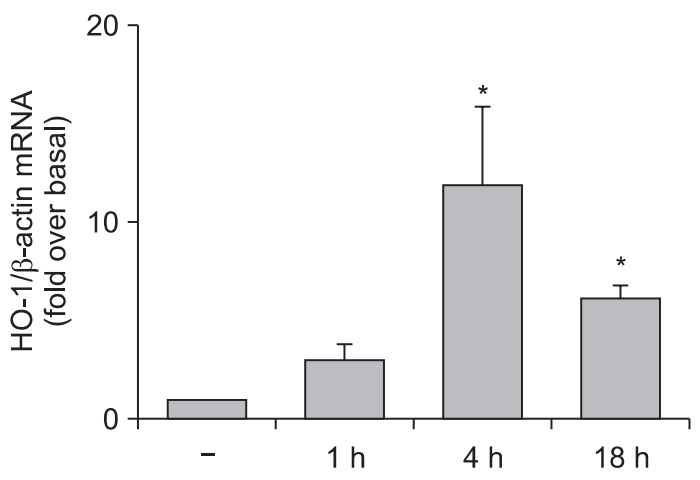

Fig. 4. EDG treatment induces HO-1 expression and nuclear accumulation of Nrf2 in RAW 264.7 macrophages. (A) Time-dependent induction of HO-1 protein by EDG treatment. RAW 264.7 macrophages were treated with EDG $(100 \mu \mathrm{M})$ for the indicated time periods. HO-1 expression was analyzed by Western blot analysis. $\beta$-actin was used for loading control. Images are representative of three independent experiments. (B) Effect of EDG on HO-1 mRNA accumulation. RAW 264.7 macrophages were cultured with $100 \mu \mathrm{M}$ of EDG for the indicated time periods, and accumulated HO-1 mRNA was measured by real time RT-PCR. Values represent HO-1 mRNA normalized to $\beta$-actin mRNA, and are expressed as means \pm S.D. $n=3$. * $p<0.05$ compared with control sample. (C) RAW 264.7 macrophages were treated with EDG $(100 \mu \mathrm{M})$ for indicated time periods. Nuclear fractions were prepared and Nrf2 protein levels were examined by Western blot analysis. $\beta$-actin was used as a loading control. Images are representative of three independent experiments. 


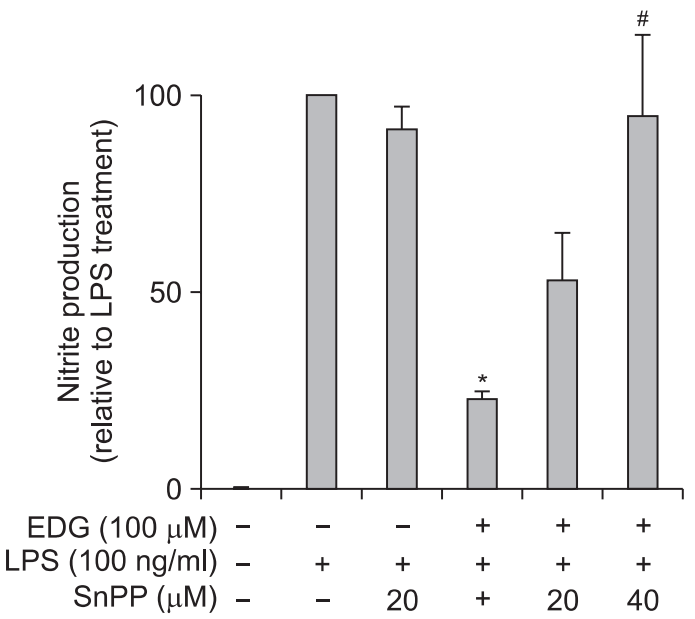

Fig. 5. EDG-mediated suppression of NO production is modulated by HO- 1 induction. RAW 264.7 macrophages were incubated with $100 \mu \mathrm{M}$ of EDG for $1 \mathrm{~h}$, followed by treated with SnPP for an additional $4 \mathrm{~h}$. The cells were further stimulated with LPS $(100 \mathrm{ng} / \mathrm{ml})$ for $20 \mathrm{~h}$. Nitrite in the cell culture media were measured. Values are expressed as relative change compared to samples treated with LPS alone, means S.D. $n=3 .{ }^{*} p<0.05$ compared with LPS treated samples, $\# p<0.05$ compared with samples treated with EDG and LPS

expression. These data suggest that Nrf2 can be considered as a transcription factor involved in $\mathrm{HO}-1$ induction by EDG.

\section{HO-1 induction mediates the suppressive effect of EDG on the inhibition of nitrite production in LPS-stimulated RAW 264.7 macrophages}

To verify HO-1 induction is implicated in EDG-mediated suppression of nitrite production, we investigated whether blocking of HO-1 is sufficient to restore the nitrite production using SnPP, a selective inhibitor of HO-1. As shown in Fig. 5, EDG suppressed LPS-induced nitrite production in macrophages consistent with previous observations. This inhibitory effect was restored in the presence of SnPP in a dose-dependent manner. SnPP $(20 \mu \mathrm{M})$ did not affect restoration of nitrite production significantly, but $40 \mu \mathrm{M}$ of SnPP significantly restore nitrite production (compare $4^{\text {th }}$ and $6^{\text {th }}$ column), while SnPP alone did not significantly affect LPS-induced nitrite production ( $3^{\text {th }}$ column), implying that the inhibitory effect of EDG on LPS-induced nitrite production is mediated, at least in part, by $\mathrm{HO}-1$ induction.

\section{DISCUSSION}

Nitric oxide (NO) plays an important role in regulating many physiological functions, such as blood vessel relaxation, inhibition of platelet aggregation and neurotransmission. However, overproduction of NO can provoke various pathological states, including inflammatory disease (Ruan, 2002). Therefore, development of the pharmacological agent interfering with NO production is considered as a useful strategy for the treatment of inflammatory disease.

We have previously shown that equilibrium mixture of ethyl $m$-digallate and ethyl $p$-digallate isomers (EDG), isolated by bioassay-guided fractionation of the ethanol extract of Galla
Rhois, exhibited potent cytoprotective effects on tacrine- and nitrofurantonin-induced cyotoxicity in HepG2 cells (An et al., 2005). In the present study, we demonstrated EDG from ethanol extract of Galla Rhois potently suppressed production of $\mathrm{NO}$ and iNOS expression in LPS-stimulated macrophages, indicating the anti-inflammatory property of EDG. In addition, we have found that ethyl gallate, another compound isolated from ethanol extract of Galla Rhois, also potently suppressed NO and iNOS expression (manuscript submitted), implying that Galla Rhois may possess a number of effective components suppressing production of inflammatory mediators and would be a promising herbal medicine for the treatment of inflammatory-associated disease.

A growing number of studies have shown that $\mathrm{HO}-1$ is a crucial antioxidant enzyme (Ryter and Tyrrell, 2000) and plays a significant role in the regulation of inflammation (Paine et al., 2010). Further, the anti-inflammatory effects of various plantderived substances work through the induction of $\mathrm{HO}-1$ ( $\mathrm{Hsu}$ et al., 2008; Lee et al., 2009). In the present study, we also clearly demonstrated that EDG isolated from Galla Rhois inhibits $\mathrm{NO}$ production through $\mathrm{HO}-1$ induction, confirming the critical role of $\mathrm{HO}-1$ in the regulation of inflammatory responses. At this stage, the mechanisms underlying suppression of nitrite production by HO-1 induction are not clear. Previous studies have shown that $\mathrm{HO}-1$ induction suppresses nitrite production through inhibition of iNOS expression (Dijkstra et al., 2004; Son et al., 2005), while other studies have demonstrated that HO-1 induction does not directly correlate with suppression of iNOS transcription (Alcaraz et al., 2004; Sawle et al., 2005). Further studies are required to investigate the mechanisms how HO-1 induction is involved in EDG-mediated suppression of nitrite production.

Nrf2 plays a crucial role in the expression of $\mathrm{HO}-1$. In the present study, we have shown that EDG treatment enhanced expression level of Nrf2 in nucleus, which correlated with an increase in HO-1 expression. Regulation of Nrf2 activity involves two different proposed mechanisms. Release of Nrf2 from its inhibitor keap1, resulting in translocation of Nrf2 to the nucleus, is a well-known mechanism involved in activation of $\mathrm{Nrf2}$. On the other hand, stimulating protein expression of Nrf2 appears to be another possible mechanism. Some natural anti-oxidant agents have been shown to increase protein expression level of Nrf2 (Kwak et al., 2002; Nguyen et al., 2003; Stewart et al., 2003). In the present study, we have shown that treatment with EDG enhanced the level of Nrf2 in nucleus (Fig. 4C). Further, EDG treatment increases the level of Nrf2 protein in cytosol fraction and total extracts (data not shown), implying that EDG works by induction of Nrf2 protein expression, rather than translocation to the nucleus.

In the present study, we demonstrated a potent inhibitory effect of EDG on nitrite production. Recent studies have shown that different types of gallic acid-derived constituents inhibit various inflammatory mediators, including cyclooxygenase-2, TNF- $\alpha$ and iNOS (Lin and Lin, 1997; Jung et al., 2010; Tipoe et al., 2010). It would be interesting to examine inhibitory effects of EDG and other gallic acid-derived components on inflammatory responses in vivo, which produce valuable information about what component would be the most effective for the treatment of inflammation-associated diseases.

In conclusion, we prepared EDG from ethanol extract of Galla Rhois and assessed its anti-inflammatory activities. EDG potently inhibited NO production in LPS-stimulated RAW 
264.7 macrophages. This effect was mediated by $\mathrm{HO}-1$ induction. Thus, EDG may be a promising agent for the treatment of inflammatory disease and further studies are required to examine the effects of EDG on the inflammation-associated disease in an in vivo model.

\section{ACKNOWLEDGMENTS}

This work was supported by the 2010 Yeungnam University Research Grant.

\section{REFERENCES}

Alcaraz, M. J., Vicente, A. M., Araico A., Dominguez J. N., Terencio M.C. and Ferrandiz, M. L. (2004) Role of nuclear factor-kappaB and heme oxygenase-1 in the mechanism of action of an anti-inflammatory chalcone derivative in RAW 264.7 cells. Br. J. Pharmacol. 142, 1191-1199.

An, R. B., Oh, H. and Kim, Y. C. (2005) Phenolic constituents of galla Rhois with hepatoprotective effects on tacrine- and nitrofurantoininduced cytotoxicity in Hep G2 cells. Biol. Pharm. Bull. 28, 21552157.

Ata, N., Oku, T., Hattori, M., Fujii, H., Nakajima, M. and Saiki, I. (1996) Inhibition by galloylglucose (GG6-10) of tumor invasion through extracellular matrix and gelatinase-mediated degradation of type IV collagens by metastatic tumor cells. Oncol. Res. 8, 503-511.

Colasanti, M. and Suzuki, H. (2000) The dual personality of NO. Trends. Pharmacol. Sci. 21, 249-252.

Deaciuc, I. V., Doherty, D. E., Burikhanov, R., Lee, E. Y., Stromberg, A J., Peng, X. and de Villiers, W. J. (2004) Large-scale gene profiling of the liver in a mouse model of chronic, intragastric ethanol infusion. J. Hepatol. 40, 219-227.

Dijkstra, G., Blokzijl, H., Bok, L., Homan, M., van Goor, H., Faber, K N., Jansen, P. L. and Moshage, H. (2004) Opposite effect of oxidative stress on inducible nitric oxide synthase and haem oxygenase-1 expression in intestinal inflammation: anti-inflammatory effect of carbon monoxide. J. Pathol. 204, 296-303.

Hsu, H. Y., Chu, L. C., Hua, K. F. and Chao, L. K. (2008) Heme oxygenase-1 mediates the anti-inflammatory effect of Curcumin within LPS-stimulated human monocytes. J. Cell. Physiol. 215, 603-612.

Jung, H. J., Kim, S. J., Jeon, W. K., Kim, B. C., Ahn, K., Kim, K., Kim, Y. M., Park, E. H. and Lim, C. J. (2010) Anti-inflammatory Activity of n-Propyl Gallate Through Down-regulation of NF-kappaB and JNK Pathways. Inflammation. 34, 352-361.

Kang, M. S., Oh, J. S., Kang, I. C., Hong, S. J. and Choi, C. H. (2008) Inhibitory effect of methyl gallate and gallic acid on oral bacteria. $J$. Microbiol. 46, 744-750.

Kroncke, K. D., Fehsel, K. and Kolb-Bachofen, V. (1997) Nitric oxide: cytotoxicity versus cytoprotection--how, why, when, and where? Nitric. Oxide. 1, 107-120.

Kwak, M. K., Itoh, K., Yamamoto, M. and Kensler, T. W. (2002) Enhanced expression of the transcription factor Nrf2 by cancer chemopreventive agents: role of antioxidant response element-like sequences in the nrf2 promoter. Mol. Cell Biol. 22, 2883-2892.

Lee, S. H., Kim, J. Y., Seo, G. S., Kim, Y. C. and Sohn, D. H. (2009) Isoliquiritigenin, from Dalbergia odorifera, up-regulates anti-inflammatory heme oxygenase-1 expression in RAW264.7 macrophages. Inflamm. Res. 58: 257-262.

Lee, S. H., Seo, G. S. and Sohn, D. H. (2004) Inhibition of lipopolysaccharide-induced expression of inducible nitric oxide synthase by butein in RAW 264.7 cells. Biochem. Biophys. Res. Commun. 323, 125-132.

Lin, Y. L. and Lin, J. K. (1997) (-)-Epigallocatechin-3-gallate blocks the induction of nitric oxide synthase by down-regulating lipopolysaccharide-induced activity of transcription factor nuclear factor-kappaB. Mol. Pharmacol. 52, 465-472.

Lowenstein, C. J., Dinerman, J. L. and Snyder, S. H. (1994) Nitric oxide: a physiologic messenger. Ann. Intern. Med. 120, 227-237.

Maines, M. D. (1997) The heme oxygenase system: a regulator of second messenger gases. Annu. Rev. Pharmacol. Toxicol. 37, 517554.

Mashimo, H. and Goyal, R. K. (1999) Lessons from genetically engineered animal models. IV. Nitric oxide synthase gene knockout mice. Am. J. Physiol. 277, G745-G750.

Melgarejo, E., Medina, M. A., Sanchez-Jimenez, F. and Urdiales, J. L. (2010) Targeting of histamine producing cells by EGCG: a green dart against inflammation? J. Physiol. Biochem. 66, 265-270.

Murase, T., Kume, N., Hase, T., Shibuya, Y., Nishizawa, Y., Tokimitsu, I. and Kita, T. (1999) Gallates inhibit cytokine-induced nuclear translocation of NF-kappaB and expression of leukocyte adhesion molecules in vascular endothelial cells. Arterioscler. Thromb. Vasc. Biol. 19, 1412-1420.

Nguyen, T., Sherratt, P. J., Huang, H. C., Yang, C. S. and Pickett, C. B. (2003) Increased protein stability as a mechanism that enhances Nrf2-mediated transcriptional activation of the antioxidant response element. Degradation of Nrf2 by the $26 \mathrm{~S}$ proteasome. J. Biol. Chem. 278, 4536-4541.

Otterbein, L. E., Soares, M. P., Yamashita, K. and Bach, F. H. (2003) Heme oxygenase-1: unleashing the protective properties of heme. Trends Immunol. 24, 449-455.

Paine, A., Eiz-Vesper, B., Blasczyk, R. and Immenschuh, S. (2010) Signaling to heme oxygenase-1 and its anti-inflammatory therapeutic potential. Biochem. Pharmacol. 80, 1895-1903.

Prawan, A., Kundu, J. K. and Surh, Y. J. (2005) Molecular basis of heme oxygenase-1 induction: implications for chemoprevention and chemoprotection. Antioxid. Redox. Signal 7, 1688-1703.

Radtke, O. A., Kiderlen, A. F., Kayser, O. and Kolodziej, H. (2004) Gene expression profiles of inducible nitric oxide synthase and cytokines in Leishmania major-infected macrophage-like RAW 264.7 cells treated with gallic acid. Planta. Med. 70, 924-928.

Ruan, R. S. (2002) Possible roles of nitric oxide in the physiology and pathophysiology of the mammalian cochlea. Ann. N. Y. Acad. Sci. 962, 260-274.

Ryter, S. W. and Tyrrell, R. M. (2000) The heme synthesis and degradation pathways: role in oxidant sensitivity. Heme oxygenase has both pro- and antioxidant properties. Free Radic. Biol. Med. 28, 289-309.

Sawle, P., Foresti, R., Mann, B. E., Johnson, T. R., Green, C. J. and Motterlini, R. (2005) Carbon monoxide-releasing molecules (CO$\mathrm{RMs}$ ) attenuate the inflammatory response elicited by lipopolysaccharide in RAW264.7 murine macrophages. Br. J. Pharmacol. 145, $800-810$

Son, E., Jeong, J., Lee, J., Jung, D. Y., Cho, G. J., Choi, W. S., Lee, M. S., Kim, S. H., Kim, I. K. and Suk, K. (2005) Sequential induction of heme oxygenase-1 and manganese superoxide dismutase protects cultured astrocytes against nitric oxide. Biochem. Pharmacol. 70, 590-597.

Stewart, D., Killeen, E., Naquin, R., Alam, S. and Alam, J. (2003) Degradation of transcription factor $\mathrm{Nrf2}$ via the ubiquitin-proteasome pathway and stabilization by cadmium. J. Biol. Chem. 278, 23962402.

Tipoe, G. L., Leung, T. M., Liong, E. C., Lau, T. Y., Fung, M. L. and Nanji, A. A. (2010) Epigallocatechin-3-gallate (EGCG) reduces liver inflammation, oxidative stress and fibrosis in carbon tetrachloride (CCl4)-induced liver injury in mice. Toxicology 273, 45-52. 